and within the buffer zone of the Machiguenga and Ashaninka Communal reserves as well as Otishi National Park.

FFI's interest in an ecosystem approach is driven by the need to expand risk management practices and corporate commitment to understand risks at earlier stages in project life-cycles, and, by changes in legislation, promote the valuation of ecosystem services (e.g. in Peru the Ley de Mecanismos de Retribución por Servicios Ecosistémicos; www.minam.gob.pe/wp-content/uploads/2014/o6/ley_302105_ MRSE.pdf). Repsol and other partners are being supported by FFI to achieve best practice through voluntary compliance with IPIECA guidelines (IPIECA is the global oil and gas industry association for environmental and social issues), following Performance Standard 6 and the adoption of an ecosystem approach in projects.

An ecosystem approach (as defined by the Convention on Biological Diversity) encourages project proponents to look at the underlying ecological structure and function that determine habitat types and biodiversity, and at the ecosystem services that stakeholders depend on within an area. Focusing on ecosystem services provides a way to integrate and connect related social and environmental indicators, and helps in the development of impact assessments, mitigation, and social and environmental projects. Through a high-level assessment of operational impacts and infrastructure development, FFI evaluates ecosystem services that both the company's operations and communities depend upon and may affect. The company's social and biodiversity baselines are reviewed, experiences of the social and environmental teams captured within an ecosystem services review workshop, and a joint site visit undertaken.

In the Sagari Project several unique activities undertaken within the social and environmental teams were applicable to the identification and understanding of ecosystem services within the study area (e.g. monitoring related to water quality, size of fish catches and hunting frequency) but lacked any focus on understanding ecosystem services. Recommendations for integrating the ecosystem approach at both the company and operational level were provided by FFI, including designing data collection to define the location and flow of ecosystem services and the level of dependence on ecosystem services by the project and local communities. A key strength of this project was a multidisciplinary approach that included participation of the Project Construction, Safety and Environment, and Community Relations teams. This resulted in a better understanding of ecosystem services across the project area and of the potential impacts the gas pipeline project will have on biodiversity and ecosystem services.

FFI engages with all its corporate partners to adopt and incorporate an ecosystem approach to identifying and managing impacts on biodiversity and ecosystem services. This current collaboration has demonstrated how the successful integration of an ecosystem approach can foster multi-disciplinary collaboration to promote the efficient and comprehensive identification of ecosystem services, stakeholder dependencies, potential impacts and mitigation activities.

Helen Nyul, Erin Parham and Pippa Howard Fauna \& Flora International, Cambridge, UK

E-mail helen.nyul@fauna-flora.org

\section{Release of confiscated and captive-bred parrots: is it ever acceptable?}

In October 2013111 captive Endangered red-and-blue lories Eos histrio were confiscated from a Filipino trader on their native island of Talaud, north of Sulawesi, Indonesia. To prevent them escaping the trader had torn out their flightfeathers, so they were transferred to recover at Tasikoki, an animal rescue centre in Sulawesi, pending their eventual release back into the wild. The Indonesian authorities emphasized the signal such a release would send to the region's trappers and traders: commerce in this species is illegal under national and international law. Thus in August 2014 55 birds (the others having died or failed to recover from their injuries) were duly liberated into forest on Talaud. Most conservation-minded onlookers would doubtless applaud this outcome, not just for the sake of the birds themselves or the species as a whole, but also for that strong conservation message. But what if this exercise sent something else back to Talaud as well?

Parrots regularly carry undetected pathogens such as herpesvirus, circovirus, polyomavirus, bornavirus and chlamydia. Even clinically healthy birds can transmit pathogens both within and between species, causing severe illness, especially in naïve (previously unexposed) populations. Moreover, some pathogens (e.g. herpesvirus) produce weak symptoms in one species but fatal ones in another. As parrots are typically sociable, disease spread can be rapid in both captivity and the wild, mostly by direct contact but even by using the same perches; in captivity airborne transmission may also occur. Detecting all potential pathogens in captive birds is expensive, time-consuming and nigh impossible, as cases can still go undetected, however comprehensive the monitoring. Unsurprisingly, therefore, many pathogens are present in many facilities worldwide. Before or even after confiscation, is it certain those lories were never housed with or near other parrots?

The experts say: 'Only in the very unusual circumstances where history of disease exposure of confiscated birds is known..., there is a true conservation need..., and there are resources for a comprehensive release programme, is it advisable to utilize confiscated birds in releases' (Snyder et al., 2000, Parrots: Status Survey and Conservation 
Action Plan 2000-2004. IUCN, Gland, Switzerland). Even so, although the problem of disease transfer may be getting worse (e.g. Jackson et al., 2014, Emu, 114, 283-289), the World Parrot Trust recently outlined its 'release to restore' plans for several species, sometimes to free confiscated wildcaught parrots in areas from which the species in question have disappeared, but sometimes to release birds that are expected eventually to unite with their wild counterparts.

An example is the proposed release of six Critically Endangered blue-throated macaws Ara glaucogularis into the species' only known area in Beni, Bolivia. World Parrot Trust's PsittaScene (May 2013, 10-11) argues that, because so few wild birds remain, the release will constitute a reintroduction, not a reinforcement (sensu IUCN/SSC, 2013, Guidelines for Reintroductions and Other Conservation Translocations, v. 1.o), because 'contact with any wild bird is unlikely to occur soon after release'. But, given that macaws are spiritedly long-distance travellers (e.g. Bonilla-Ruz et al., 2007, Wilson Journal of Ornithology, 119, 729-732), how small should this unlikelihood be? What constitutes 'soon'? Confiscated grey parrots Psittacus erithacus released at Lake Victoria were, within 3 months, 'regularly mixing and flying with a small group of wild birds' (PsittaScene August 2014, 13-14). If (1) some parrot diseases incubate for many months, (2) some healthy birds are life-long carriers, and (3) some cases escape detection however carefully screened, how confident can we be that releasing the macaws serves the best interests of the species?

When confiscated birds are involved the alternatives are far from pleasant: deployment to zoos for education, lifelong care at a centre, or-most depressingly-euthanasia (although this is illegal in Indonesia for threatened species). All the more reason, therefore, that any release programme must observe the highest levels of scrutiny for pathogens (Jakob-Hoff et al., 2014, Manual of Procedures for Wildlife Disease Risk Management. OIE, Paris, France), keeping birds in secure quarantine for $3^{-6}$ months and retesting them at least twice for different diseases according to circumstance. Without such rigour, can the risk posed by captive birds to any targeted wild population-especially if the only population-ever be acceptable?

Nigel J. Collar BirdLife International, Cambridge, UK E-mailnigel.collar@birdlife.org

Michael Lierz Clinic for Birds, Reptiles, Amphibians and Fish, Justus-Liebig-Universität Giessen, Germany

MARK R. Stanley PRICE WildCRU, University of Oxford, Oxford, UK

ROLAND Z. WIRTH ZGAP, Munich, Germany

\section{New evidence of dhole Cuon alpinus populations in north-west China}

As a happy consequence of snow leopard surveys being conducted by our teams across China, we are pleased to report important new evidence of populations of the dhole Cuon alpinus from two sites in north-west China. The first is from camera-trapping surveys in the Shulenan Mountain range in Yanchiwan National Nature Reserve on the northern edge of the Qinghai-Tibetan Plateau in Gansu Province. Here, on two occasions, we have recorded a single female with at least two pups. The first photographs, in May 2013, showed a female with two pups $<_{1}$ month old. The second set of photographs, in July 2013, showed a female with two older pups, perhaps 3 months old. The timing is consistent with these being the same individuals, as is the distance between the camera stations of $4.5 \mathrm{~km}$. However, as there were no distinguishing features visible, we were unable to determine conclusively whether these were the same individuals. Further photographs taken between January 2013 and May 2014 revealed dhole packs of at least five individuals within the Reserve. It is not possible to determine how many packs live in this area. Information about dholes has also been reported by local livestock herders and confirmed by local staff within the Reserve. These reports suggest two or more packs of up to 30 individuals live in this area. Photographs and reported sightings in Yanchiwan occurred at elevations of c. 2,500-4,000 m.

It was also recently brought to our attention that during 2011-2013 livestock herders and local government officials reported dholes in the vicinity of Taxkorgan Nature Reserve, in the Karakoram/Pamir Mountain region of Xinjiang Autonomous Region, on China's border with Pakistan, Tajikistan and Afghanistan. The accuracy of these reports has been confirmed, with herders able to distinguish between pictures of the dhole (referred to in Mandarin as chái: 烸) and the wolf (láng: 狼). Packs of 7-30 dholes were sighted on six occasions in areas to the east of Taxkurgan at c. 2,000-3,500 m. Nine incidences of livestock depredation by dholes were reported during this period, with sheep and yak being the targeted prey. Pack sizes associated with depredation events were reported to be between three and 'more than 20' individuals.

With as few as 2,500 mature individuals remaining in the wild, mostly in South and South-east Asia, and populations thought to be in decline, these new records of the dhole extend the known range for the species significantly. The existence of the population on the northern edge of the Qinghai-Tibetan Plateau had been suspected, although unconfirmed, since a reported sighting in 2003. There have been no recent records of dholes from the Karakorum/ Pamir region and so the new evidence is important. We are now undertaking more detailed surveys for this species 